\section{The emerging evidence for non-skeletal health benefits of vitamin D supplementation in adults}

\author{
William B. Grant (D, Barbara J. Boucher(D, Pawel Pludowski and \\ Sunil J. Wimalawansa (i)
}

The Review by Bouillon et al. on health effects of vitamin D supplementation reported that vitamin D supplementation of vitamin D-replete adults (that is, with baseline serum concentrations of 25-hydroxyvitamin D $(25 \mathrm{OHD})>50 \mathrm{nmol} / \mathrm{l}$ ) does not reduce cancer, cardiovascular events, falls or progression to type 2 diabetes mellitus (T2DM) (Bouillon, R. et al. The health effects of vitamin D supplementation: evidence from human studies. Nat. Rev. Endocrinol. 18, 96-110 (2022) $)^{1}$ ). We suggest that this statement is incorrect based on other findings.

Randomized clinical trials (RCTs) of vitamin D supplementation were mostly designed to test vitamin D dosage. Heaney's guidelines for clinical studies of nutrient effects ${ }^{2,3}$ showed that vitamin D supplementation trials should instead be designed and analysed by serum concentrations of $25 \mathrm{OHD}$. Data from the D2d study ${ }^{4}$ of vitamin D supplementation (4,000 IU per day) in patients with prediabetes were re-analyzed by achieved serum concentrations of $25 \mathrm{OHD}^{5}$. This re-analysis changed negative overall findings for progression to T2DM after vitamin D supplementation ${ }^{4}$ to a hazard ratio (HR) for T2DM of 0.48 (95\% CI, 0.29-0.80) for those who maintained 25OHD of 100-124 nmol/L and 0.29 (95\% CI, $0.17-0.50$ ) for those who maintained 25OHD $>125 \mathrm{nmol} / \mathrm{l}$, compared with $25 \mathrm{OHD}$ levels of 50-75 nmol/l (REF. ${ }^{5}$ ).

One Canadian observational study involving 8,155 participants investigated the association between achieved serum concentrations of 25OHD and blood pressure ${ }^{6}$. Participants were given vitamin $\mathrm{D}_{3}$ supplements and counselled on how to achieve 25OHD levels $>100 \mathrm{nmol} / \mathrm{l}$. Mean baseline 25OHD level was $87 \pm 37 \mathrm{nmol} / \mathrm{l}$, final $25 \mathrm{OHD}$ was $113 \pm 39 \mathrm{nmol} / 1$ and $33 \%$ of participants took $>8,000$ IU of vitamin $\mathrm{D}_{3}$ per day. After 1 year, $71 \%$ of the 592 participants with hypertension were normotensive, with $13 \pm 19 \mathrm{~mm} \mathrm{Hg}$ and $11 \pm 10 \mathrm{~mm} \mathrm{Hg}$ systolic and diastolic blood pressures, respectively, lower than baseline blood pressures.

Breast cancer incidence was inversely and significantly correlated with serum concentrations of 25OHD in a meta-analysis using data from two vitamin $\mathrm{D}$ supplementation RCTs and one cohort study ${ }^{7}$. The pooled cohort included 5,038 women, 77 of whom were diagnosed with breast cancer during the studies. Multivariate Cox regression showed that women with $25 \mathrm{OHD}$ levels $\geq 150 \mathrm{nmol} / \mathrm{l}$ had a HR for breast cancer of 0.20 (95\% CI, $0.05-0.82)$ compared with women with $25 \mathrm{OHD}$ levels of $\leq 50 \mathrm{nmol} / \mathrm{l}$.

For myocardial infarction and all-cause mortality, a 20-year retrospective analysis of patients of the US Veterans Health Administration with a baseline 25OHD levels of $<50 \mathrm{nmol} / \mathrm{l}$, with or without counselling to supplement with vitamin $\mathrm{D}^{8}$ showed that those with a serum concentration of $25 \mathrm{OHD}$ $>75 \mathrm{nmol} / \mathrm{l}$ had a propensity-matched HR for myocardial infarction of 0.73 (95\% CI, $0.55-0.96)$ and a HR for all-cause mortality of 0.61 (95\% CI, 0.56-0.67), compared with those with $25 \mathrm{OHD}$ levels $<50 \mathrm{nmol} / \mathrm{l}$.

Mendelian randomization studies were included in Bouillon et al. ${ }^{1}$ Review. We suggest these studies have limited ability to assess the effects of nutrients, as they do not allow for the nonlinear effects on 25OHD and do not account for high variance in $25 \mathrm{OHD}$ assays. 25OHD-stratified analyses allow for nonlinearity and have revealed decreased cardiovascular disease risk with increased serum levels of $25 \mathrm{OHD}$ in non-vitamin D replete individuals from the UK Biobank ${ }^{9}$.

In conclusion, vitamin D supplementation RCTs and Mendelian randomization studies have provided limited support for health benefits of serum levels of $25 \mathrm{OHD}>50 \mathrm{nmol} / \mathrm{l}$; however, additional analyses of RCT data suggest that this finding is largely due to problems with how those studies were designed and analysed. Thus, guidance is warranted on vitamin $\mathrm{D}$ intake to achieve $25 \mathrm{OHD}$ $>75 \mathrm{nmol} / \mathrm{l}^{10}$.

There is a reply to this letter by Bouillon, $\mathrm{R}$. et al. Nat Rev. Endocrinol. https://doi.org/ 10.1038/s41574-022-00647-w (2022).

William B. Grant iD ${ }^{1 凶}$, Barbara J. Boucher (iD ${ }^{2 凶}$, Pawel Pludowski ${ }^{3 凶}$ and Sunil J. Wimalawansa iD ${ }^{4 \times}$ ${ }^{\prime}$ Sunlight, Nutrition, and Health Research Center, San Francisco, CA, USA.

${ }^{2}$ The Blizard Institute, Queen Mary University of London, London, UK.

${ }^{3}$ Department of Biochemistry, Radioimmunology and Experimental Medicine, The Children's Memorial Health Institute, Warsaw, Poland. ${ }^{4}$ Cardio-Metabolic \& Endocrine Institute, North Brunswick, NJ, USA.

凶e-mail:wbgrant@infionline.net; bboucher@ doctors.org.uk; p.pludowski@ipczd.pl; suniljw@hotmail.com

https://doi.org/10.1038/s41574-022-00646-x

. Bouillon, R. et al. The health effects of vitamin D supplementation: evidence from human studies. Nat. Rev. Endocrinol. 18, 96-110 (2022).

2. Heaney, R. P. Guidelines for optimizing design and analysis of clinical studies of nutrient effects. Nutr. Rev. 72, 48-54 (2014).

3. Grant, W. B., Boucher, B. J., Bhattoa, H. P. \& Lahore, H. Why vitamin D clinical trials should be based on 25-hydroxyvitamin D concentrations. J. Steroid Biochem. Mol. Biol. 177, 266-269 (2018).

4. Pittas, A. G. et al. Vitamin D Supplementation and Prevention of Type 2 Diabetes. N. Engl. J. Med. 381, 520-530 (2019).

5. Dawson-Hughes, B. et al. Intratrial Exposure to Vitamin D and New-Onset Diabetes Among Adults With Prediabetes: A Secondary Analysis From the Vitamin D and Type 2 Diabetes (D2d) Study. Diabetes Care 43, 2916-2922 (2020).

6. Kimball, S. M., Mirhosseini, N. \& Holick, M. F. Evaluation of vitamin D3 intakes up to 15,000 international units/day and serum 25-hydroxyvitamin D concentrations up to $300 \mathrm{nmol} / \mathrm{L}$ on calcium metabolism in a community setting. Dermatoendocrinol. 9, e1300213 (2017).

7. McDonnell, S. L. et al. Breast cancer risk markedly lower with serum 25-hydroxyvitamin D concentrations $\geq 60 \mathrm{vs}<20 \mathrm{ng} / \mathrm{ml}$ ( $150 \mathrm{vs} 50 \mathrm{nmol} / \mathrm{L}$ ): Pooled analysis of two randomized trials and a prospective cohort. PLoS One 13, e0199265 (2018).

8. Acharya, P. et al. The Effects of Vitamin D Supplementation and 25-Hydroxyvitamin D Levels on the Risk of Myocardial Infarction and Mortality. J. Endocr. Soc. 5, bvab124 (2021).

9. Zhou, A., Selvanayagam, J. B. \& Hyppönen, E. Non-linear Mendelian randomization analyses support a role for vitamin $\mathrm{D}$ deficiency in cardiovascular disease risk. Eur. Heart J. https://doi.org/10.1093/ eurheartj/ehab809 (2021).

10. Pludowski, P. et al. Vitamin D supplementation guidelines. J. Steroid Biochem. Mol. Biol. 175, 125-135 (2018).

\section{Competing interests}

W.B.G.'s non-profit organization, Sunlight, Nutrition and Health Research Center, receives funding from Bio-Tech Pharmacal, Inc. (Fayetteville, AR, USA). All other authors declare no competing interests. 